\title{
Prostate Cancer: The Role of Multiparametric Magnetic Resonance Imaging
}

\author{
Cancro da Próstata: O Papel da Ressonância Magnética Multiparamétrica
}

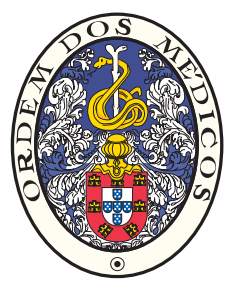

\author{
João LOPES DIAS ${ }^{1}$, João MAGALHÃES PINA², Raquel JOÃO², Joana FIALHO'1, Sandra CARMO'1, Cecília LEAL¹, \\ Tiago BILHIM ${ }^{1}$, Rui MATEUS MARQUES ${ }^{1}$, Luís CAMPOS PINHEIRO² \\ Acta Med Port 2015 Mar-Apr;28(2):240-249
}

\section{ABSTRACT}

Multiparametric Magnetic Resonance Imaging has been increasingly used for detection, localization and staging of prostate cancer over the last years. It combines high-resolution T2 Weighted-Imaging and at least two functional techniques, which include Dynamic Contrast-Enhanced Magnetic Resonance Imaging, Diffusion-Weighted Imaging, and Magnetic Resonance Imaging Spectroscopy. Although the combined use of a pelvic phased-array and an Endorectal Coil is considered the state-of-the-art for Magnetic Resonance Imaging evaluation of prostate cancer, Endorectal Coil is only absolute mandatory for Magnetic Resonance Imaging Spectroscopy at 1.5 T. Sensitivity and specificity levels in cancer detection and localization have been improving with functional technique implementation, compared to T2 Weighted-Imaging alone. It has been particularly useful to evaluate patients with abnormal PSA and negative biopsy. Moreover, the information added by the functional techniques may correlate to cancer aggressiveness and therefore be useful to select patients for focal radiotherapy, prostate sparing surgery, focal ablative therapy and active surveillance. However, more studies are needed to compare the functional techniques and understand the advantages and disadvantages of each one. This article reviews the basic principles of prostatic mp-Magnetic Resonance Imaging, emphasizing its role on detection, staging and active surveillance of prostate cancer.

Keywords: Diffusion Magnetic Resonance Imaging; Magnetic Resonance Imaging; Prostatic Neoplasms.

\section{RESUMO}

A Ressonância Magnética Multiparamétrica tem sido crescentemente utilizada na detecção, localização e estadiamento do cancro da próstata. Combina sequências T2 de alta-resolução com pelo menos duas técnicas funcionais, que incluem o estudo dinâmico pós-gadolínio, a difusão e a espectroscopia. O protocolo ideal aconselha a utilização combinada de uma antena de superfície e uma endorectal; contudo, a antena endorectal é apenas obrigatória para a realização de espectroscopia em aparelhos de 1,5 T. Os níveis de sensibilidade e especificidade na detecção e localização do cancro da próstata têm aumentado com a inclusão das técnicas funcionais, quando comparados com as sequências T2 isoladas, o que é particularmente vantajoso em doentes que têm biópsia negativa, apesar de níveis de PSA persistentemente elevados. Para além disso, a informação adicionada pelas técnicas funcionais aparenta correlacionar-se com a agressividade tumoral, podendo tornar-se útil na selecção de doentes radioterapia focal, cirurgias conservadoras, terapias de ablação focal e vigilância activa. Contudo, são necessários mais estudos para comparar as várias técnicas funcionais e compreender as vantagens e desvantagens de cada uma. Este artigo pretender rever os princípios básicos da Ressonância Magnética prostática multiparamétrica, enfatizando o seu papel na detecção, estadiamento e vigilância activa do cancro da próstata.

Palavras-chave: Imagem de Difusão por Ressonância Magnética; Neoplasias da Próstata; Ressonância Magnética.

\section{INTRODUCTION}

Magnetic Resonance Imaging (MRI) has been considered a primary non-invasive imaging tool for the evaluation of the prostate gland on the basis of its high soft tissue contrast. ${ }^{1-6}$ Its use for detection, localization and staging of prostate cancer has been increasing over the last years; in many centers, it has been essentially used when there's high cancer suspicion despite negative transrectal ultrasound (TRUS) guided biopsy findings. ${ }^{7,8}$ Actually, patients with abnormal PSA and negative biopsy represent a particular population, which simultaneously needs a high sensitivity evaluation (able to accurately pinpoint cancers missed at biopsy) and an imaging tool with high negative predictive value (in order to avoid an unnecessary repeat biopsy). ${ }^{9}$

The value of MRI on prostate cancer has however been extended to cases of recurrence suspicion, active surveillance, refused biopsy, MRI-guided biopsy, and also
MRI-US fusion technology to improve the accuracy of USguided biopsies. ${ }^{6,10-15}$

Although morphological MRI including $\mathrm{T} 1$ and $\mathrm{T} 2$ weighted-imaging (WI) has been widely used for the pretreatment study of prostate cancer, this technique has some limitations and improvement in sensitivity and specificity for cancer detection and localization may be achieved in combination with functional techniques such as dynamic contrast-enhanced MR imaging (DCE), diffusionweighted imaging (DWI), and MR spectroscopy (MRS). The combination of T2WI with at least two of these techniques is known as multiparametric MRI (mp-MRI).,2, 6, 16-18

Optimal MR imaging for detection and local staging of prostate cancer requires the use of an endorectal coil (ERC) combined with a pelvic phased-array coil (PPA) with a minimum of 16 channels, on a magnet with a field strength

1. Department of Radiology. Hospital de São José. Centro Hospitalar Lisboa Central. Lisboa. Portugal.

2. Department of Urology. Hospital de São José. Centro Hospitalar Lisboa Central. Lisboa. Portugal.

Recebido: 23 de Março de 2014 - Aceite: 21 de Julho de 2014 | Copyright ( ๑ Ordem dos Médicos 2015 
of at least 1.5 Tesla $(\mathrm{T})$. Prostate imaging at $3 \mathrm{~T}$ benefits from higher signal to noise ratios (SNR), improving image resolution and acquisition speed without the use of ERC; however, some technical limitations related to susceptibility artifacts and inhomogeneity of the magnetic field may exist, and further research is needed. ${ }^{1,6,7}$

One of the advantages of ERC is the significant increase in capsular delineation, visualization of the neurovascular bundle (facilitating nerve-sparing decisions) and rectoprostatic angle, which may not only improve the general staging performance (reducing overstaging), but also accurately delineate cancer foci in the planning of intensity-modulated radiation therapy and enable radiation boosting to areas within the prostate. ${ }^{19,20}$ The levels of sensitivity and specificity are variable and depend on the centers and the studies, which reflect the differences on expertise, equipment, study protocols, diagnostic criteria and accuracy of pathologic correlations. ${ }^{2}$

Despite the advantages of the ERC, there's no absolute consensus about it and some authors suggest that its use might not be mandatory when the main interest is tumor detection and localization, consequently saving time and costs, and probably causing less distortion of prostate gland. Moreover, the use of a PPA alone for signal reception would cause less discomfort for the patient. ${ }^{3,9,19}$ According to recent guidelines from ESUR (European Society of Urogenital Radiology), despite the combined use of a PPA and an ECR constitutes the state-of-the-art for MRI evaluation of prostate cancer, ECR is only absolute mandatory for MR spectroscopy (MRS) at $1.5 \mathrm{~T}$, remaining optional at $3 \mathrm{~T}$ and for other techniques at $1.5 \mathrm{~T}^{6}$

At our institution, we perform mp-MRI on a $1.5 \mathrm{~T}$ body scanner (Magneton Avanto; Siemens) with a $33 \mathrm{mT} / \mathrm{m}$ maximum attainable amplitude using an eight channel PPA. The study of the pelvis includes an axial turbo spin-eco T1WI imaging for nodal disease and postbiopsy intraglandular hemorrhage detection (5 mm; gap $1.0 \mathrm{~mm}$; repetition time [TR] 450 ms; eco time [TE] 7.9 ms; FOV 40 cm; matrix 269 $x$ 384), and also an axial Blade T2WI with fat saturation (FS) (5 mm; gap 1.0 mm; TR 4760 ms; TE 120 ms; FOV $36 \mathrm{~cm}$; number of blades 20) which improves nodal disease and bone metastasis detection. With regard to the prostate gland study, we perform a set of axial, coronal and sagital high-resolution T2WI (3 mm; gap 0.6 mm; TR 4000 ms; TE $103 \mathrm{~ms}$; FOV $20 \mathrm{~cm}$; matrix $310 \times 320$ ). An axial DWI is performed with b factors of $50,800,1000$ and $1200 \mathrm{~s} / \mathrm{mm} 2$ (3.5 mm; gap 0.7 mm; TR 5100 ms; TE 88 ms; FOV 45 $\mathrm{cm}$; matrix $150 \times 192$ ). The DCE-MRI is performed with an axial fat-saturated 3D Vibe T1W MR sequence (26 slabs; slice oversampling $23 \%$, dist factor $20 \%$; $3.5 \mathrm{~mm}$; TR 4.84 ms; TE 1.69 ms; FOV $26 \mathrm{~cm}$; matrix 138 x 192), after bolus injection of gadoterate meglumine, with a dose of $0.2 \mathrm{mmol} /$ $\mathrm{kg}$ of body weight.

\section{MR Imaging Appearance of Normal Prostate Anatomy}

MRI may depict the zonal anatomy of the prostate with great detail due to its high spatial resolution, superior contrast resolution, multiplanar capability, and large field of view. ${ }^{3,21}$

On T1WI, generally obtained only in the axial plane, the prostate demonstrates homogeneous low-to-medium signal intensity and the zonal anatomy is impossible to discern. In contrast, T2WI should be obtained in three planes (axial, coronal and sagittal) and is able to depict the zonal anatomy (Fig. 1). The peripheral zone, which represents the major glandular component of the prostate and composes $70 \%$ of the prostate in healthy young men, appears high in signal on T2WI, whereas the central gland (CG) has lower signal intensity because of its compactly arranged smooth muscle and loose glandular tissue. The CG includes the transitional zone (TZ), which constitutes only about $5 \%$ of the glandular prostate, and central-periurethral (CZ) zone, which makes up about $25 \%$ of the glandular prostate. The anterior fibromuscular stroma also has low signal intensity on T2WI. ${ }^{1,2,7,16,21}$

The peripheral and transition zones are separated by a visible linear boundary often referred as pseudocapsule or surgical capsule. The true prostate capsule surrounds the peripheral zone and appears as a hypointense rim in T2WI. (Fig. 1) The neurovascular bundles are seen posterolateral to the prostate capsule and possess both high and low signal intensity foci. The seminal vesicles appear as hyperintense on $\mathrm{T} 2 \mathrm{WI}$, whereas the paired vas deferens are low in signal intensity. The distal prostatic urethra appears as a low-signal-intensity ring in the lower prostate, but the proximal urethra is rarely identifiable. ${ }^{1,7,16,21}$

\section{MR Imaging Appearance of Prostate Cancer}

T2WI has been most effective for peripheral tumors,

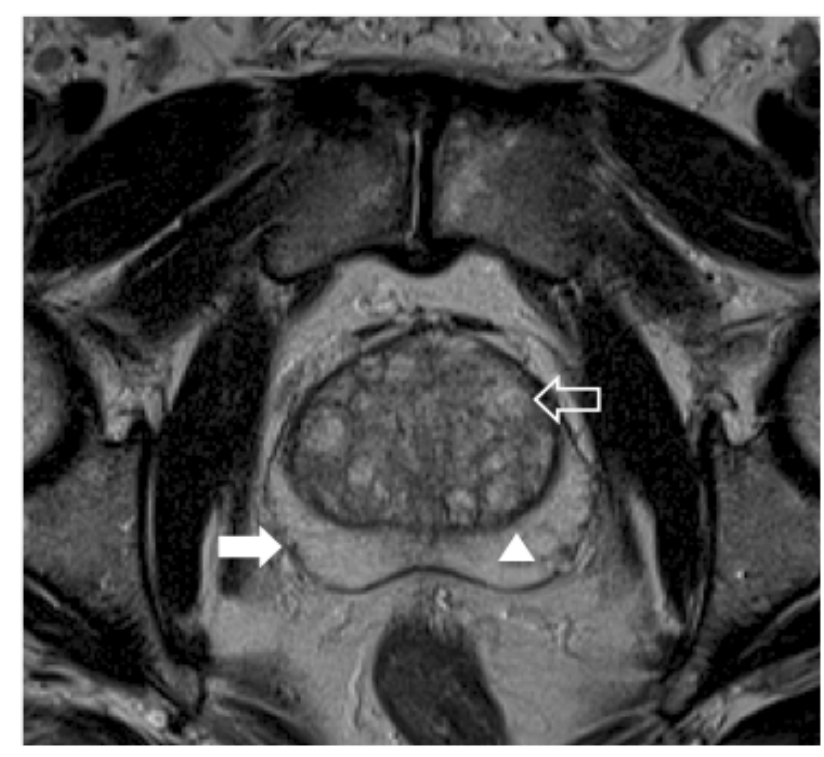

Figure 1 - Axial T2WI depicts the normal zonal anatomy. The peripheral zone appear hyperintense and homogeneous (arrow), clearly separated from the central gland by a pseudocapsule (arrowhead). A true hypointense capsule rims the entire gland. In this case, some features of benign hyperplasia are seen: heterogeneous transitional and central zones, with some intermediate signal intensity nodules circumscribed by hypointense halos (open arrow). 
which accounts for $70 \%$ of prostate adenocarcinomas. On T2WI, tumors usually appear as low signal round or ill-defined areas within the normal high-signal intensity peripheral zone (Fig.s 2a, 2b, 3a). In contrast, tumors and great part of prostatic abnormalities are not identified on T1WI; however, this sequence may be advantageous by showing post-biopsy hemorrhage, which is almost always hyperintense in relation to the normal parenchyma (Fig. 6b). . $^{1-3,7,16,18,21}$

In the transition and central zones, which accounts respectively for $20 \%$ and $10 \%$ of adenocarcinomas, T2WI shows significant limitations for depicting cancer, because cancer and normal tissue both have low signal intensity. ${ }^{18,22}$ Nevertheless, it is also possible to detect cancer in the transition zone, especially when conventional $\mathrm{MRI}$ is combined with MR spectroscopic imaging and other

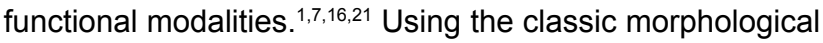
MRI, there are some findings that may support the diagnosis of a central prostate tumor, like the existence of a homogeneous low-signal intensity region in the transition zone (Fig. 5a), poorly defined or spiculated lesion margins, the lack of the typical low-signal-intensity rim seen in benign adenomatous nodules, the interruption of the surgical pseudocapsule, lenticular shape (while benign nodules are usually round) and urethral or anterior fibromuscular stromal invasion. . $^{1,3,7,22,23}$
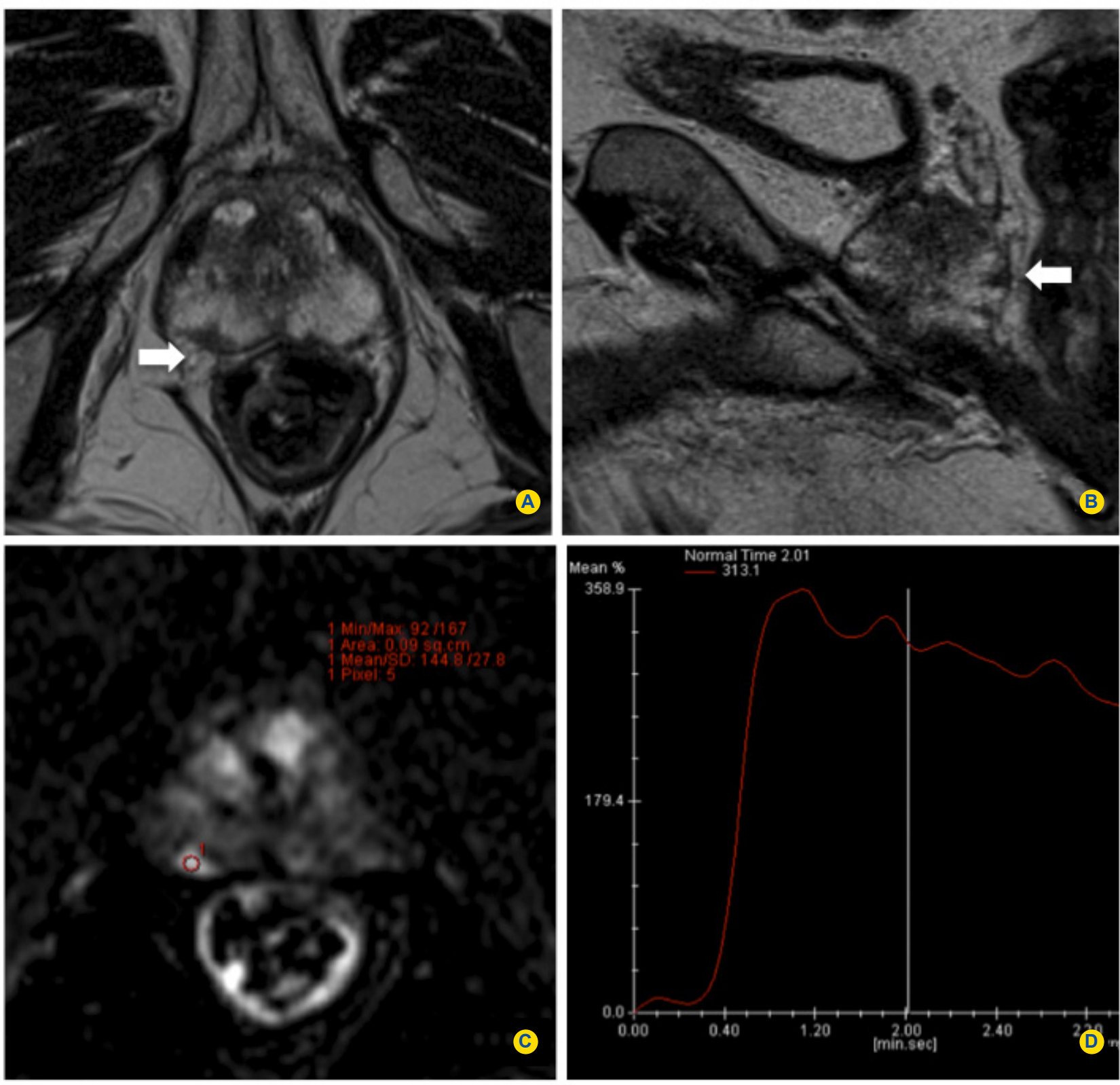

Figure 2 - Images in a 76-year-old man with persistent high PSA level of $11 \mathrm{ng} / \mathrm{mL}$ and an initial negative biopsy. Axial and sagittal T2WI $(A, B)$ show an $11 \mathrm{~mm}$ hypointense nodule within the right peripheral zone (arrows). The suspicious area demonstrates early enhancement on DCE $(C)$ and the obtained time-signal intensity curve (x-axis, time in seconds; $y$-axis, signal intensity in mean percentage) (D) shows a moderate washout following the fast and high peak enhancement. The second biopsy, under cognitive MR-TRUS fusion, revealed an adenocarcinoma (Gleason score of 6). 
There are various conditions that can mimic cancer on $\mathrm{T} 2 \mathrm{WI}$, such as prostatitis, hemorrhage, atrophy, benign hyperplasia, post-radiation therapy fibrosis and changes after hormone deprivation therapy. Although post-biopsy hemorrhage may mimic tumors on $\mathrm{T} 2 \mathrm{WI}$, it generally shows high signal intensity on T1WI, which does not happen with cancer. (Fig.s 6a, 6b). However, post-biopsy hemorrhage may hamper tumor detection and staging, by under or overestimating tumor presence and local extent, both on T2WI and on functional tools such as DCE and MRS. Since the usual abundant citrate in normal prostate has an anticoagulant effect, blood products may persist 4-6 weeks or longer after prostate biopsy, so a delay of 6-8 weeks after biopsy is usually recommended. ${ }^{1,2,7,16,21,24}$ Some authors recommend the acquisition of preliminary T1WI in order to exclude significant post-biopsy hemorrhage. If relevant hemorrhage is found, MRI examination may be rescheduled 3-4 weeks later. ${ }^{6}$

In the evaluation of extracapsular extension (ECE), seminal vesicle invasion (SVI) and bladder neck invasion, high resolution $\mathrm{T} 2 \mathrm{WI}$ in axial, coronal and sagittal planes should be used in combination. Sagittal images improve the evaluation of tumors located at the apex and base. ECE can be detected on T2WI by visualizing direct extension of the tumor into the periprostatic fat, but there are other criteria that include neurovascular bundle asymmetry, tumor envelopment of the neurovascular bundle, contour angulation, an irregular or speculated margin, obliteration of the rectoprostatic angle, capsular retraction, and evidence of direct tumor extension to the capsule (Fig.s 4a, 4b, 5a). MRI has been reported to have $13 \%-95 \%$ sensitivity and $49 \%$ $97 \%$ specificity for detection of ECE. This huge variability may be related to the different expertise levels and technica protocols applied by distinct centers. The recent attempt on establishing clinical guidelines and optimal techniques is likely to achieve high and uniform sensitivity and specificity levels. ${ }^{3}$

The features of SVI on MR images include the extension of tumor from the base of prostate, the presence of focal low signal intensity within the normal high signal seminal vesicles, disruption or loss of the normal SV architecture, enlarged low-signal-intensity ejaculatory ducts, enlarged low-signal intensity seminal vesicle and obliteration of the angle between the prostate and the seminal vesicle (Fig $5 b)$. Sensitivity and specificity for detection of SVI are variable depending on the study, ranging from 20 to $80 \%$ and from 81 to $99 \%$, respectively. ${ }^{1,3,7,25,26}$

The invasion of adjacent organs like bladder and rectum is also identified by MR imaging and optimized with sagittal imaging planes. ${ }^{21}$
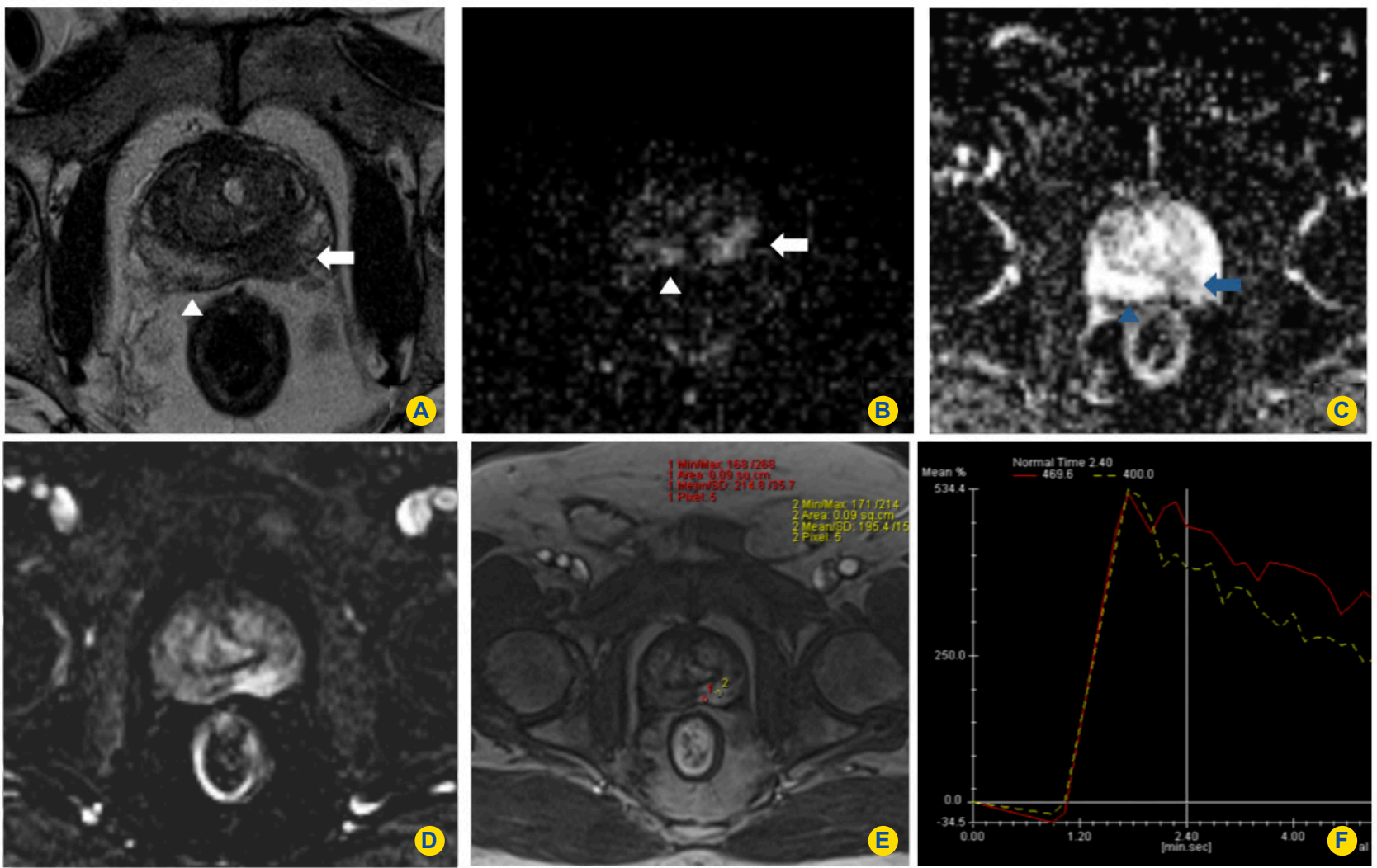

Figure 3 - Images in a 73-year-old man with PSA level of $18,4 \mathrm{ng} / \mathrm{mL}$ and biopsy-proven adenocarcinoma with Gleason score of 7 . Axial $\mathrm{T} 2 \mathrm{WI}(\mathrm{A})$ shows a $10 \mathrm{~mm}$ hypointense suspicious nodule within the left peripheral zone (arrows). The lesion appears as bright and dark on corresponding raw diffusion weighted (B) and apparent diffusion coefficient (ADC) maps (C), respectively (arrows). In the right peripheral zone, a smaller tumoral focus may be seen, sharing the same characteristics on T2WI, DWI, and ADC map (arrowheads). DCE images $(D, E)$ demonstrate enhancement of the tumor focus. Two regions of interest were placed and time-signal intensity curves were obtained ( $x$-axis, time in seconds; $y$-axis, signal intensity in mean percentage) $(F)$, showing fast and high peak enhancement followed by a marked washout (type 3 curves). 

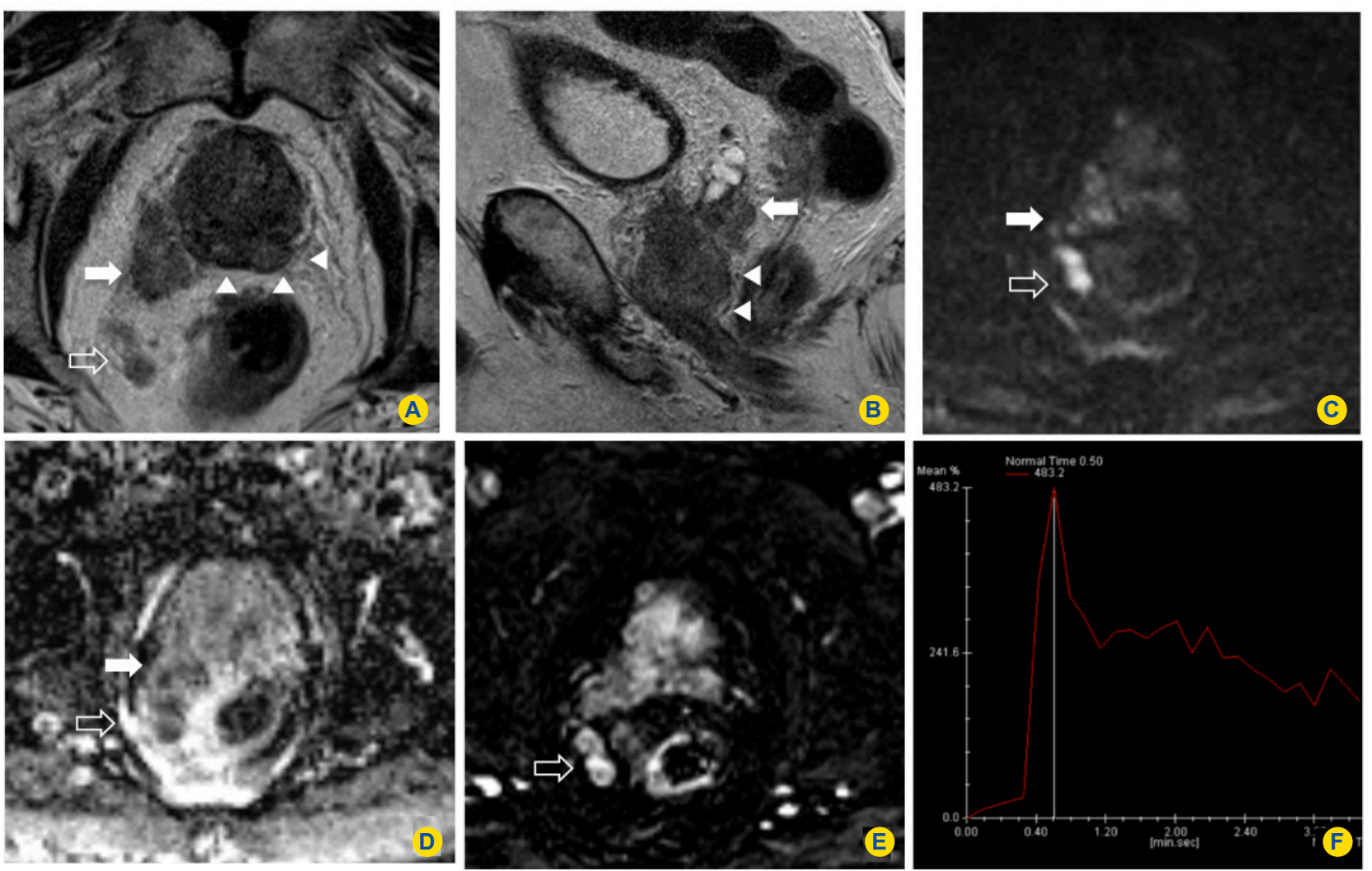

Figure 4 - Images in a 76-year-old man with PSA level of 15,6 ng/mL and biopsy-proven adenocarcinoma (Gleason score of 7). Axial and sagittal T2WI $(A, B)$ show diffuse peripheral hypointensity (arrowheads) and a right basal prostate bulging compatible with extracapsular extension (arrows). This area demonstrates high signal intensity on high b-value DWI (C) and appears dark on corresponding ADC map (D) (arrows). DCE images (E,F) demonstrate fast and heterogeneous enhancement and highly suspicious, type 3, time-signal intensity curves. Pathological right para-rectal tumor deposits were also identified.

\section{Dynamic contrast-enhanced (DCE) MR imaging}

The tumor angiogenesis and the characteristic surrounding interstitial environment can be used as a diagnostic marker of disease, altering the enhancement pattern after contrast administration. 1,7,16 The cancerous tissue has an increased number of vessels due to the production and release of angiogenic factors (vascular permeability growth factor or vascular endothelial growth factor) and its permeability is greater than normal vessels. $3,16,27,28$

DCE MR imaging provides direct depiction of tumor vascularity. A full dose $(0.1 \mathrm{mmol} / \mathrm{kg})$ of gadolinium is generally injected at $3 \mathrm{~mL} / \mathrm{sec}$, and serial $3 \mathrm{D}$ acquisitions are obtained every $2-5$ seconds through the prostate. That way, it is possible to display quantitative kinetic parameters reflecting contrast washin and washout, including onset time, time to peak, peak enhancement, relative peak enhancement (comparing to normal tissue), and washout time. . $^{1,7,16,21}$

Tumors often demonstrate early nodular enhancement before the rest of the parenchyma and early washout of signal intensity, a pattern which is highly predictive of prostate cancer despite being non pathognomonic. This washout pattern corresponds to a type 3 enhancement curve. A type 2 enhancement curve (plateau) may be also associated to malignancy, while a type 1 (steadily rising) curve is unlikely malignant (Fig.s 2c-d, 3d-f, 4e-f). ${ }^{1,6,7,76,28}$

Engelbrecht et $\mathrm{al}^{27}$ demonstrated that the relative peak enhancement was the most accurate perfusion parameter for cancer detection in the peripheral zone and central region of the gland. The detection of areas of enhancement on early postcontrast images (within the first $30-60$ seconds after contrast material injection) constitutes a qualitative feature and may also be used to detect cancer. ${ }^{21}$

When carcinoma has spread throughout the prostate, normal prostatic tissue cannot be used as a reference and consequently it is not possible to use relative peak enhancement. In these cases, peak enhancement can be used as the parameter in the PZ, and washout can be used as the parameter in the CG. Peak enhancement is not ideal in $C G$ because of the high peak enhancement levels usually found in normal CG tissue. ${ }^{27}$

Some studies like that of Kim et $\mathrm{al}^{29}$ demonstrated that dynamic contrast-enhancement analysis was more accurate for the detection of prostate cancer in the peripheral zone than conventional T2-weighted imaging alone. DCE alone has reported variable sensitivity and specificity, ranging of $52-96 \%$ and $65-95 \%$, respectively, which is probably related to different patient selection criteria, as well as distinct protocols and analytic techniques applied. ${ }^{3,9,30}$

DCE MRI has an important limitation: the insufficient depiction of transitional zone cancer in patients with 
hypervascular benign prostatic hyperplasia because abnormal enhancement patterns may be seen in both tumors and benign nodules. ${ }^{16,29}$ Moreover, smaller and low grade tumors may not demonstrate abnormal enhancement on DCE, and some prostate tumors are only mildly or moderately hypervascular, and thus are not detectable through this technique. ${ }^{16}$

DCE MRI can also be used for the detection of postprostatectomy and post-radiotherapy recurrences, and for determining the effectiveness of hormone deprivation therapy, which tends to reduce the tumor permeability and to change the tissue washout pattern..$^{6,16,28,31}$
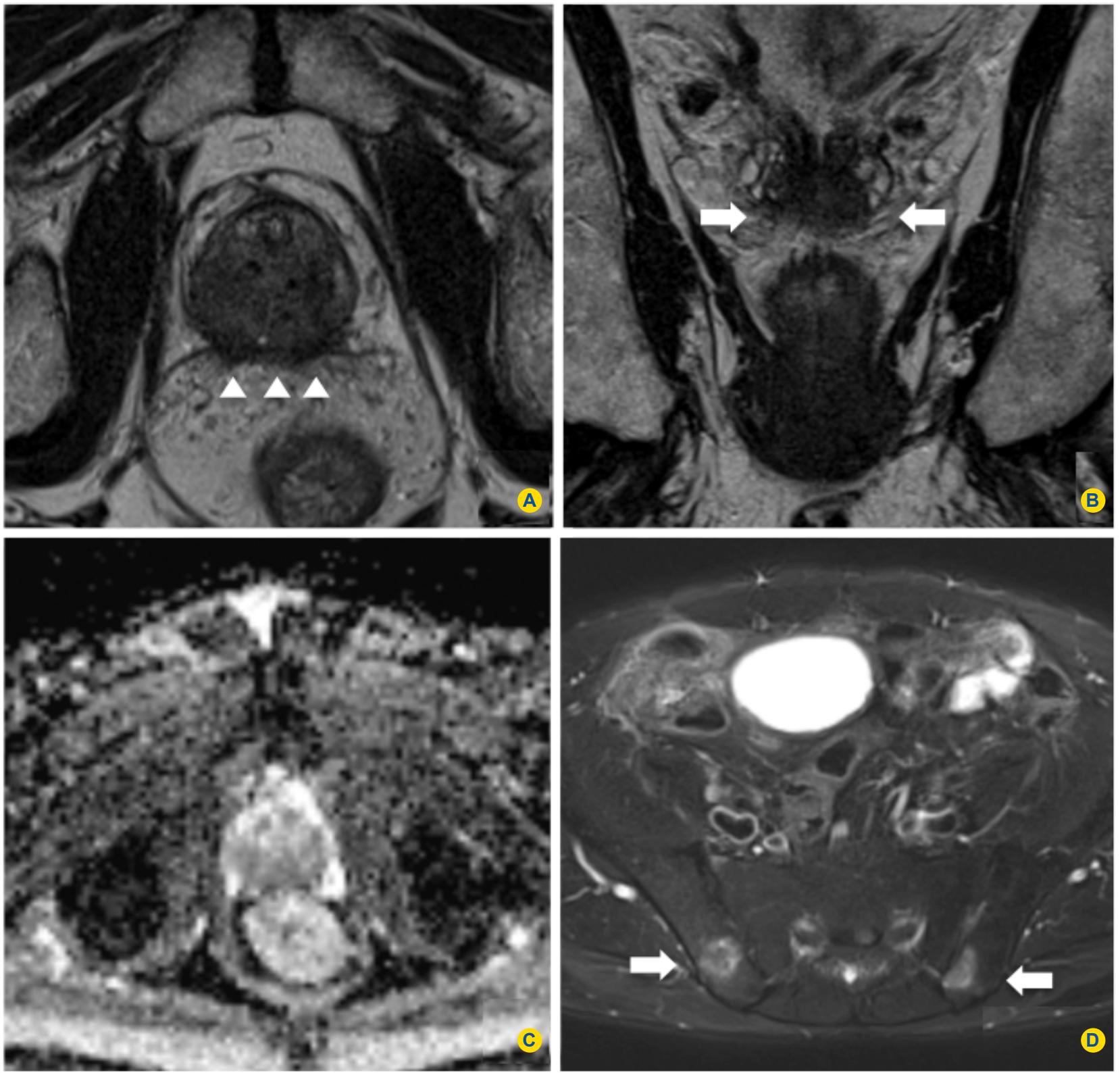

Figure 5 - Images in 71-year-old man with PSA level of $12.6 \mathrm{ng} / \mathrm{mL}$ and biopsy-proven adenocarcinoma (Gleason score of 9). Unenhanced axial (A) and coronal (B) T2WI show a large hypointense tumor in the base of the prostate, with obliteration of the pseudocapsule and extension to the transition zone. There is also diffuse bulging and irregularity of the posterior prostate contour and mild, low-signal intensity enlargement of the seminal vesicles, findings highly suggestive of posterior ECE (arrowheads, a) and SVI (arrows, b). ADC map (C) shows diffuse low ADC values. Axial T2WI with fat-supression (D) shows bilateral hyperintense iliac bone metastasis (arrows). 
fibrotic stroma, which constitutes an inhibitory environment to the movement of water. ${ }^{16,32,33}$

The differences in water diffusion rates between normal and tumoral tissues can be depicted and quantitatively represented by apparent diffusion coefficient (ADC) maps, which are obtained with at least two $b$ values. Restricted diffusion typically seen in prostate cancer leads to high signal on raw high $b$ value DWI and low signal intensity on ADC maps (Fig.s 3b-c, 4c-d, 5c). 3,18

The $b$ value refers to the strength of the diffusion sensitizing gradient, which means that at $a b$ value of 0 $\mathrm{sec} / \mathrm{mm} 2$ there's no gradient. At low b value, free water molecules have high signal intensity and the signal intensity is based on T2 weighting. At high b values, such as 1000 $\mathrm{sec} / \mathrm{mm} 2$, only the water molecules with restricted diffusion retain their high signal and persist bright on DWI, as may occur within a tumour. There is no absolute consensus about the optimal b value for prostate cancer detection, but it is known that higher $b$ values may increase diffusion sensitivity by lowering the normal hyperintensity of tissues with long $\mathrm{T} 2$ relaxation times, such as the $\mathrm{PZ} .{ }^{32-35}$

Several studies showed significant differences in the mean ADC values between cancerous and normal tissues for the PZ and to a lesser extent for the TZ (36). However, other studies showed considerable overlap of ADC values between prostate cancer and benign conditions like $\mathrm{BPH}$ and
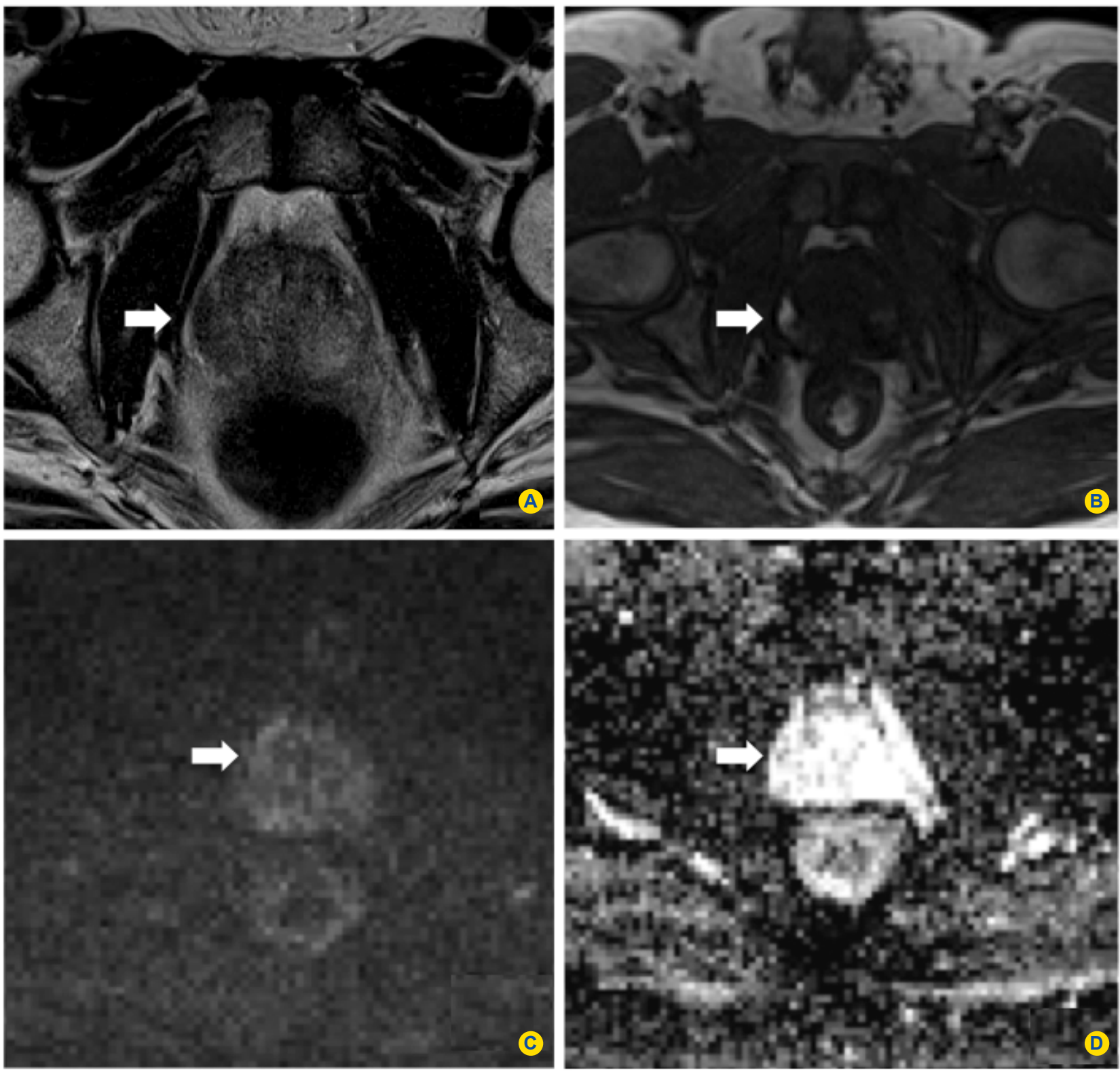

Figure 6 - Images in 62-year-old man with PSA level of $6.54 \mathrm{ng} / \mathrm{mL}$ and biopsy-proven adenocarcinoma (Gleason score of 7). Axial T2WI (A) shows a moderately hypointense area within the left peripheral zone (open arrow). This area is hyperintense on T1WI (B), shows non-suspicious high signal on the ADC map (C) and demonstrates no relevant enhancement on DCE (D), corresponding to post-biopsy hemorrhage (open arrows). By contrast, a tumor is found within the right peripheral zone (arrows), showing marked hypointensity on T2WI $(A)$, low ADC values (C), and strong enhancement on DCE (D). 
prostatitis. ${ }^{16,18,34,37-44}$ There is also evidence of a significant negative correlation between the ADC values of prostate tumors and prostatectomy specimen Gleason scores. Bittencourt et $\mathrm{al}^{32}$ suggested that $A D C$ values perform better than TRUS guided biopsy Gleason scores in the correlation with prostatectomy Gleason scores. However, individual variability may decrease the diagnostic accuracy of ADC measurement for prostate cancer detection and localization. ${ }^{16}$

According to Shimofusa et al, ${ }^{35}$ the use of DWI in addition to T2WI significantly improved the accuracy of tumor detection when compared to T2WI alone, with an area under the curve of 0.93 for the combined imaging techniques and 0.87 for T2WI alone. Moreover, adding DWI seems to significantly improve the accuracy of prostate peripheral tumor volume measurement. ${ }^{45}$

The main advantage of DWI is the high contrast resolution between tumors (which appear bright) and normal tissue. Nevertheless, this technique is limited by susceptibility to hemorrhage, gas, peristalsis, and detrusor contraction artifacts. The lack of anatomical references is also limiting but may be overcome through the fusion of high b-value images and T2WI. ${ }^{16}$

\section{Targeted prostate biopsies and active surveillance}

TRUS-guided prostate biopsy with 10-12 samples remains the gold standard for detecting prostate cancer. However, this standard technique has some limitations. First, it misses $30-40 \%$ of prostate tumors located in the anterior lateral peripheral zone, in the transition zone or in the anterior fibromuscular stroma. Second, it may miss significant cancer, even in the peripheral zone, and some non-clinically significant cancers (low volume and Gleason $\leq 6$ tumors) may be diagnosed. Moreover, it may not accurately predict final Gleason score, since upgrading of apparently low-grade tumors found at TRUS biopsy is common at more definitive histology. ${ }^{13,46,47}$ In this set, one of the main goals of mp-MRI is to avoid some PSA only-driven random prostate biopsies, by localizing suspicious areas for further guided procedures.

Multiparametric-MRI targeted prostate biopsies include cognitive fusion TRUS targeting, MRI-TRUS fusion targeting, and in-bore MRI-guided biopsy. Cognitive fusion targeting implies the review of MR images before the procedure by the biopsy performer. This operator dependent technique relies on the ability of the performer to mentally register the site considered on MRI at the time of TRUS biopsy. In addition, it shows an important disadvantage: several tumors are isoechogenic or only slightly hypoechogenic comparing to the surrounding gland, and therefore non visible by ultrasonography. ${ }^{46}$ Distinctly, MRI-TRUS fusion targeting is less operator-dependent, allowing a real-time fusion between US images and pre-biopsy MRI, so the target is visualized during the biopsy. MRI-guided biopsy is performed at the time of MRI and allows real-time MRI guidance. However, it is time consuming, expensive, implies MR compatible biopsy devices, and is probably associated with prostate deformation and higher patient discomfort. ${ }^{46}$

By now, the strongest indication for pre-biopsy MRI targeting is probably previously negative biopsies despite ongoing clinical suspicion of prostate cancer. The current guidelines do not recommend targeted samples only, but many studies have been developed and this is a very promising research field that may significantly change the daily practice. ${ }^{48,49}$

According to the ESUR guidelines, low risk patients (which are those with PSA $\leq 10 \mathrm{ng} / \mathrm{mL}$, biopsy Gleason score $\leq 6$, and clinical stage T1-T2a) are good candidates for active surveillance. 6 The currently used clinical protocols take into account other inclusion criteria, namely less than 3 positive core biopsy fragments (in a minimum of 12 ) and less than $50 \%$ involvement of each fragment. ${ }^{50,51}$ The main goal of active surveillance is to avoid radical treatment unless disease progresses or the patient decides to undergo treatment.10 Mp-MRI may firstly confirm the classification of risk status, by excluding unexpected larger, more aggressive, and higher-grade tumors. ${ }^{48,49}$ If the risk status is compatible, mp-MRI may be used to follow-up. Sometimes, the tumor is not visible and if it remains not seen in following MR examinations, it indicates that the development of a clinically significant cancer is implausible. When the tumor is initially identifiable, it may be monitored for change, according to several morphological and functional criteria. These criteria are not well established, since further research is needed, but the volume of the dominant focus, appearance of additional foci, changes on DCE pattern, and decreases on ADC values should be checked. ${ }^{6}$

Figure 7 summarizes the role of $\mathrm{mp}-\mathrm{MRI}$ on prostate cancer, including detection with targeted biopsies and active surveillance.

\section{CONCLUSION}

Multiparametric MRI combines conventional T1WI and high-resolution $\mathrm{T} 2 \mathrm{WI}$ with at least two functional techniques, including DCE and DWI. T2WI is a watersensitive sequence used for tumor detection and T1WI is blood-sensitive, allowing the recognition of post-biopsy hemorrhage, which may compromise diagnosis. DCE assesses tumor vascularity and DWI detects areas of restriction to the diffusion of water molecules, namely by tightly packed tumor cells.

The role of $\mathrm{mp}-\mathrm{MRI}$ in prostate cancer has been recently studied and is continually improving both clinically significant disease detection and staging. It is hoped that recent progress on technique may contribute to decrease prostate cancer mortality and morbidity by allowing better early diagnosis, and better patient selection for focused radiotherapy, focal ablative therapy, prostate sparing surgery and active surveillance. However, more studies are needed to compare the functional techniques, understand the advantages and disadvantages of each one and to assess the overall impact of MP-MR on patient outcome. 

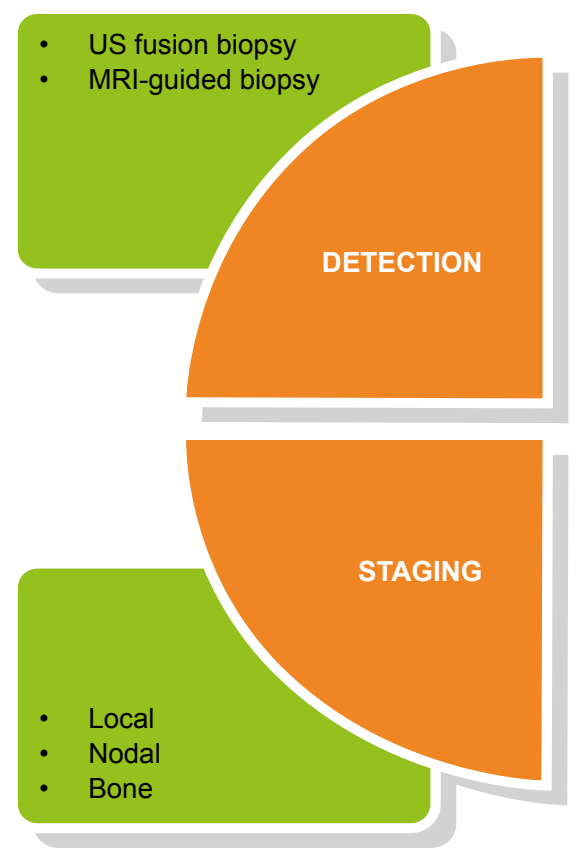

Figure 7 -Role of Multiparametric MRI on Prostate Cancer.

\section{OBSERVATIONS}

Please consider this manuscript of our work, which was presented in part at the XXIII International Symposium on Morphological Sciences, in Niigata (September 2013).

\section{REFERENCES}

1. Ravizzini G, Turkbey B, Kurdziel K, Choyke PL. New horizons in prostate cancer imaging. Eur J Radiol. 2009;70:212-26.

2. Chabanova E, Balslev I, Logager V, Hansen A, Jakobsen H, KromannAndersen $\mathrm{B}$, et al. Prostate cancer: $1.5 \mathrm{~T}$ endo-coil dynamic contrastenhanced MRI and MR spectroscopy--correlation with prostate biopsy and prostatectomy histopathological data. Eur J Radiol. 2011;80:292-6.

3. Turkbey B, Albert PS, Kurdziel K, Choyke PL. Imaging localized prostate cancer: current approaches and new developments. AJR Am J Roentgenol. 2009;192:1471-80.

4. Hegde JV, Mulkern RV, Panych LP, Fennessy FM, Fedorov A, Maier SE, et al. Multiparametric MRI of prostate cancer: an update on state-of-theart techniques and their performance in detecting and localizing prostate cancer. J Magn Reson Imaging. 2013;37:1035-54.

5. Talab SS, Preston MA, Elmi A, Tabatabaei S. Prostate cancer imaging: what the urologist wants to know. Radiol Clin North Am. 2012;50:101541.

6. Barentsz JO, Richenberg J, Clements R, Choyke P, Verma S, Villeirs G, et al. ESUR prostate MR guidelines 2012. Eur Radiol. 2012;22:746-57.

7. Hricak H, Choyke P, Eberhardt SC, Leibel SA, Scardino PT. Imaging Prostate Cancer: a multidisciplinary perspective. Radiology. 2007;243:28-53.

8. Dickinson L, Ahmed HU, Allen C, Barentsz JO, Carey B, Futterer JJ, et al. Scoring systems used for the interpretation and reporting of multiparametric MRI for prostate cancer detection, localization, and characterization: could standardization lead to improved utilization of imaging within the diagnostic pathway? J Magn Reson Imaging. 2013;37:48-58

9. Cheikh AB, Girouin N, Colombel M, Maréchal JM, Gelet A, Bissery $A$, et al. Evaluation of T2-weighted and dynamic contrast-enhanced MRI in localizing prostate cancer before repeat biopsy. Eur Radiol. 2009;19:770-8.

10. Turkbey B, Mani H, Aras O, Ho J, Hoang A, Rastinehad AR, et al Prostate cancer: can multiparametric MR imaging help identify patients who are candidates for active surveillance? Radiology. 2013;268:14452 .

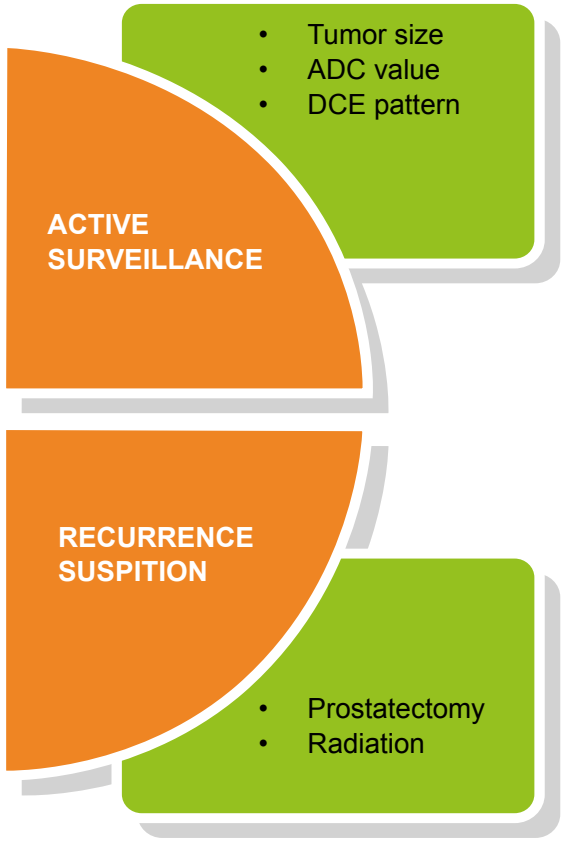

\section{CONFLICT OF INTERESTS}

None stated.

\section{FUNDING SOURCES}

None stated.

11. Jung A, Westphalen A. Imaging prostate cancer. Radiol Clin North Am Am. 2012;50:1043-59.

12. Futterer JJ. Imaging of recurrent prostate cancer. Radiol Clin North Am Am. 2012;50:1075-83.

13. Haffner J, Lemaitre L, Puech P, Haber GP, Leroy X, Jones JS, et al Role of magnetic resonance imaging before initial biopsy: comparison of magnetic resonance imaging-targeted and systematic biopsy for significant prostate cancer detection. BJU Int. 2011;108:E171-8.

14. Shimizu T, Nishie A, Ro T, Tajima T, Yamaguchi A, Kono S, et al. Prostate cancer detection: the value of performing an MRI before a biopsy. Acta Radiol. 2009:50:1080-8.

15. Sartor AO, Hricak H, Wheeler TM, Coleman J, Penson DF, Carroll PR, et al. Evaluating localized prostate cancer and identifying candidates for focal therapy. Urology. 2008;72:S12-24.

16. Choi YJ, Kim JK, Kim N, Kim KW, Choi EK, Cho K-S. Functional MR imaging of prostate cancer. RadioGraphics. 2007;27:63-75.

17. Scheidler J, Hricak H, Vigneron DB, Yu KK, Sokolov DL, Huang LR, et al. Prostate cancer: localization with three-dimensional proton MR spectroscopic imaging-clinicopathologic study. Radiology. 1999;213:473-80.

18. Chen M, Dang HD, Wang JY, Zhou C, Li SY, Wang WC, et al. Prostate cancer detection: comparison of T2-weighted imaging, diffusionweighted imaging, proton magnetic resonance spectroscopic imaging, and the three techniques combined. Acta Radiol. 2008;49:602-10.

19. Heijmink S, Futterer JJ, Hambrock T, Takahashi S, TW S, Huisman HJ. Prostate cancer: body-array versus endorectal coil MR imaging at 3 $\mathrm{T}$-comparison of image quality, localization, and staging performance. Radiology. 2007;244:184-95.

20. Fütterer JJ, Engelbrecht $M R$, Jager GJ, Hartman RP, King BF Hulsbergen-Van de Kaa CA, et al. Prostate cancer: comparison of local staging accuracy of pelvic phased-array coil alone versus integrated endorectal-pelvic phased-array coils. Local staging accuracy of prostate cancer using endorectal coil MR imaging. Eur Radiol. 2007;17:1055-65.

21. Claus FG, Hricak $H$, Hattery RR. Pretreatment evaluation of prostate cancer : role of MR imaging and $1 \mathrm{H} M R$ spectroscopy. Radiographics. 
2004;24:167-80

22. Akin O, Sala E, Moskowitz CS, Kuroiwa K, Ishill NM, Pucar D, et al. Transition zone prostate cancers: features, detection, localization, and staging at endorectal MR Imaging. Radiology. 2006;239:784-92.

23. Chesnais $A L$, Niaf $E$, Bratan $F$, Mège-Lechevallier $F$, Roche $S$, Rabilloud M, et al. Differentiation of transitional zone prostate cancer from benign hyperplasia nodules: evaluation of discriminant criteria at multiparametric MRI. Clin Radiol. 2013;68:e323-30.

24. Tamada T, Sone T, Jo Y, Yamamoto A, Yamashita T, Egashira N, et al. Prostate Cancer: relationships between postbiopsy hemorrhage and tumor detectability at MR diagnosis. Radiology. 2008;248:531-9.

25. Soylu FN, Peng Y, Jiang Y, Wang S, Schmid-Tannwald C, Sethi I, et al. Seminal vesicle invasion in prostate cancer: evaluation by using multiparametric endorectal MR imaging. Radiology. 2013;267:797-806.

26. Kim B, Kawashima A, Ryu J, Takahashi N, Hartman RP. Imaging of the seminal vesicle and vas deferens. Radiographics. 2009;29:1105-21.

27. Engelbrecht MR, Huisman HJ, Laheij RJ, Jager GJ, van Leenders GJ, Hulsbergen-Van De Kaa CA, et al. Discrimination of prostate cancer from normal peripheral zone and central gland tissue by using dynamic contrast-enhanced MR imaging. Radiology. 2003;229:248-54.

28. Alonzi R, Padhani A, Allen C. Dynamic contrast enhanced MRI in prostate cancer. Eur J Radiol. 2007;63:335-50.

29. Kim JK, Hong SS, Choi YJ, Park SH, Ahn H, Kim CS, et al. Wash-in rate on the basis of dynamic contrast-enhanced MRI: usefulness for prostate cancer detection and localization. J Magn Reson Imaging 2005;22:639-46.

30. Jager GJ, Ruijter ET, van de Kaa CA, de la Rosette JJ, Oosterhof GO, Thornbury JR, et al. Dynamic TurboFLASH subtraction technique for contrast-enhanced MR imaging of the prostate: correlation with histopathologic results. Radiology. 1997;203:645-52.

31. Del Vescovo R, Pisanti F, Russo V, Battisti S, Cazzato RL, D'Agostino $F$, et al. Dynamic contrast-enhanced MR evaluation of prostate cancer before and after endorectal high-intensity focused ultrasound. Radiol Med. 2013;118:851-62.

32. Bittencourt LK, Barentsz JO, de Miranda LC, Gasparetto EL. Prostate MRI: diffusion-weighted imaging at 1.5T correlates better with prostatectomy Gleason Grades than TRUS-guided biopsies in peripheral zone tumours. Eur Radiol. 2012;22:468-75.

33. Qayyum A. Diffusion-weighted imaging in the abdomen and pelvis: concepts and applications. Radiographics. 2009;29:1797-810.

34. Sato C, Naganawa S, Nakamura T, Kumada H, Miura S, Takizawa $\mathrm{O}$, et al. Differentiation of noncancerous tissue and cancer lesions by apparent diffusion coefficient values in transition and peripheral zones of the prostate. J Magn Reson Imaging. 2005;21:258-62.

35. Shimofusa R, Fujimoto $H$, Akamata $H$, Motoori K, Yamamoto $S$, Ueda $\mathrm{T}$, et al. Diffusion-weighted imaging of prostate cancer. J Comput Assist Tomogr. 2005;29:149-53.

36. Hoeks CM, Hambrock T, Yakar D, Hulsbergen-van de Kaa CA, Feuth T, Witjes JA, et al. Transition zone prostate cancer: detection and localization with 3-T multiparametric MR imaging. Radiology. 2013;266:207-17.

37. Nagel KN, Schouten MG, Hambrock T, Litjens GJ, Hoeks CM, ten Haken $\mathrm{B}$, et al. Differentiation of prostatitis and prostate cancer by using diffusion-weighted MR imaging and MR-guided biopsy at 3 T. Radiology. 2013;267:164-72.

38. Watanabe Y, Nagayama M, Araki T, Terai A, Okumura A, Amoh Y, et al. Targeted biopsy based on ADC map in the detection and localization of prostate cancer: a feasibility study. J Magn Reson Imaging. 2013;37:1168-77.

39. Vargas HA, Akin O, Franiel T, Mazaheri $Y$, Zheng J, Moskowitz $C$ et al Diffusion-weighted endorectal MR imaging at $3 \mathrm{~T}$ for prostate cancer: tumor detection and assessment of aggressiveness. Radiology. 2011;259:775-84.

40. Turkbey B, Shah VP, Pang Y, Bernardo M, Xu S, Kruecker J, et al. Is apparent diffusion coefficient associated with clinical risk scores for prostate cancers that are visible on 3-T MR images? Radiology. 2011;258:488-95.

41. Hambrock T, Somford DM, Huisman HJ, van Oort I, Witjes JA, Hulsbergen-Van de Kaa C. Relationship between apparent diffusion coefficients at 3.0-T MR imaging and Gleason grade in peripheral zone prostate cancer. Radiology. 2013;259:453-61.

42. Kitajima K, Takahashi S, Ueno Y, Miyake H, Fujisawa M, Kawakami F, et al. Do apparent diffusion coefficient (ADC) values obtained using high b-values with a 3-T MRI correlate better than a transrectal ultrasound (TRUS)-guided biopsy with true Gleason scores obtained from radical prostatectomy specimens for patients with prostat. Eur J Radiol. 2013;82:1219-26.

43. DeSouza N, Riches S, Vanas N, Morgan V, Ashley S, Fisher C. Diffusionweighted magnetic resonance imaging: a potential non-invasive marker of tumour aggressiveness in localized prostate cancer. Clin Radiol. 2008;63:774-82

44. Verma S, Rajesh A, Morales H, Lemen L, Bills G, Delworth M, et al. Assessment of aggressiveness of prostate cancer: correlation of apparent diffusion coefficient with histologic grade after radical prostatectomy. AJR Am J Roentgenol. 2011;196:374-81.

45. Mazaheri Y, Hricak H, Fine S, Akin O, Shukla-Dave A, Ishill NM. Prostate tumor volume measurement with combined T2-weighted imaging and diffusion-weighted MR: correlation with pathologic tumor volume. Radiology. 2009;252:449-57.

46. Ghai S, Toi A. Role of transrectal ultrasonography in prostate cancer. Radiol Clin N Am. 2012;50:1061-73.

47. Margel D, Yap SA, Lawrentschuk N, Klotz L, Haider M, Hersey K, et al. Impact of multiparametric endorectal coil prostate magnetic resonance imaging on disease reclassification among active surveillance candidates: a prospective cohort study. J Urol. 2012;187:47-1252.

48. Kirkham AP, Haslam P, Keanie JY, McCafferty I, Padhani AR, Punwani S, et al. Prostate MRI: who, when, and how? Report from a UK consensus meeting. Clin Radiol. 2013;68:1016-23.

49. Ahmed H, Kirkham A, Arya M, Illing R, Freeman A. Is it time to consider a role for MRI before prostate biopsy? Nat Rev Clin Oncol. 2009;6:197206.

50. Lawrentschuk N, Klotz L. Active surveillance for low-risk prostate cancer: an update. Nat Rev Urol. 2011;8:312-20.

51. Large M, Eggener S. Active surveillance for low-risk localized prostate cancer. Oncology. 2009;23:974-9. 
João LOPES DIAS, João MAGALHÃES PINA, Raquel JOÃO, Joana FIALHO, Sandra CARMO, Cecília LEAL, Tiago BILHIM, Rui MATEUS MARQUES, Luís CAMPOS PINHEIRO

\section{Prostate Cancer: The Role of Multiparametric Magnetic Resonance Imaging}

Acta Med Port 2015:28:240-249

Publicado pela Acta Médica Portuguesa, a Revista Científica da Ordem dos Médicos

Av. Almirante Gago Coutinho, 151

1749-084 Lisboa, Portugal.

Tel: +351218428215

E-mail: submissao@actamedicaportuguesa.com

www.actamedicaportuguesa.com

ISSN:0870-399X | e-ISSN: 1646-0758

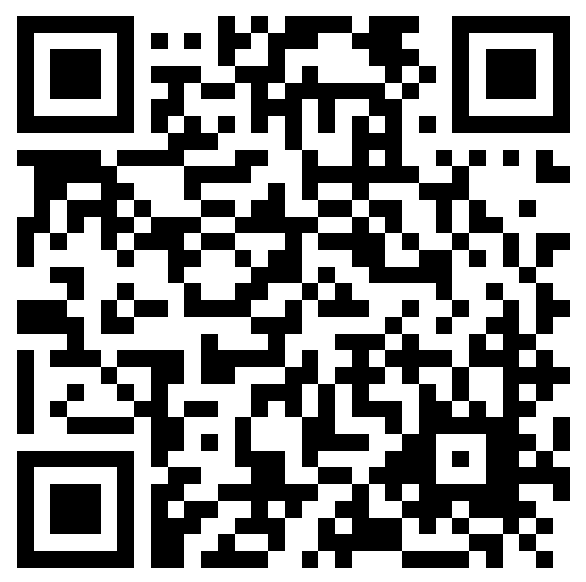

